\section{Response to: 'Bisphosphonates reduce the risk of knee replacement: we need more analyses!' by Li et al}

We thank Dr Li and colleagues ${ }^{1}$ for their interest in our paper. As outlined in our paper, ${ }^{2}$ we used data from a large general practitioner electronic health records database for our study. These data are collected and recorded as part of routine clinical care with diagnostic codes. As such, factors such as willingness to undergo and access to knee replacement (KR), knee pain severity, disability, quality of life and others are not available in this database, and we were thus unable to examine these as potential confounders. We were, however, able to account for socioeconomic status (Townsend Deprivation Index), and performed sensitivity analyses demonstrating that substantial residual confounding is unlikely. The assessment of bisphosphonate exposure was based on prescription data, and alendronate was the most common bisphosphonate prescribed $(84 \%)$, as described in the paper. ${ }^{2}$ The potential mechanisms by which bisphosphonates may confer the noted effects were beyond the scope of this paper. Nonetheless, it is not clear that bisphosphonate initiation would alter one's willingness to undergo KR or access to KR such that a protective effect would be noted in our study. We included both total and unicompartmental primary knee arthroplasty since either surgery would indicate substantially symptomatic knee osteoarthritis, but did not include revision surgery since the reasons for that procedure are not for severe/end-stage osteoarthritis; this is the same approach used by the other studies we had cited on this matter. As per standard time-to-event analyses, subjects were censored at the first KR, among the other censoring factors outlined in the paper.
Tuhina Neogi, Shanshan Li, Christine Peloquin, Devyani Misra, Yuqing Zhang

Clinical Epidemiology Unit, Boston University School of Medicine, Boston, Massachusetts, USA

Correspondence to Dr Tuhina Neogi, Clinical Epidemiology Unit, Boston University School of Medicine, Boston, MA 02118, USA; tneogi@bu.edu

Handling editor Josef S Smolen

Funding This research received no specific grant from any funding agency in the public, commercial or not-for-profit sectors.

Competing interests None declared.

Provenance and peer review Commissioned; internally peer reviewed.

(C) Article author(s) (or their employer(s) unless otherwise stated in the text of the article) 2019. All rights reserved. No commercial use is permitted unless otherwise expressly granted.

D Check for updates

To cite Neogi T, Li S, Peloquin C, et al. Ann Rheum Dis 2019;78:e16.

Received 5 February 2018

Accepted 5 February 2018

Published Online First 14 February 2018

\section{Linked}

http://dx.doi.org/10.1136/annrheumdis-2018-213052

Ann Rheum Dis 2019;78:e16. doi:10.1136/annrheumdis-2018-213094

\section{REFERENCES}

1 Li H-Z, Xu X-H, Lu H-D. Bisphosphonates reduce the risk of knee replacement: we need more analyses!. Ann Rheum Dis 2019;78:e15.

2 Neogi T, Li S, Peloquin C, et al. Effect of bisphosphonates on knee replacement surgery. Ann Rheum Dis 2018;77:92-7. 